
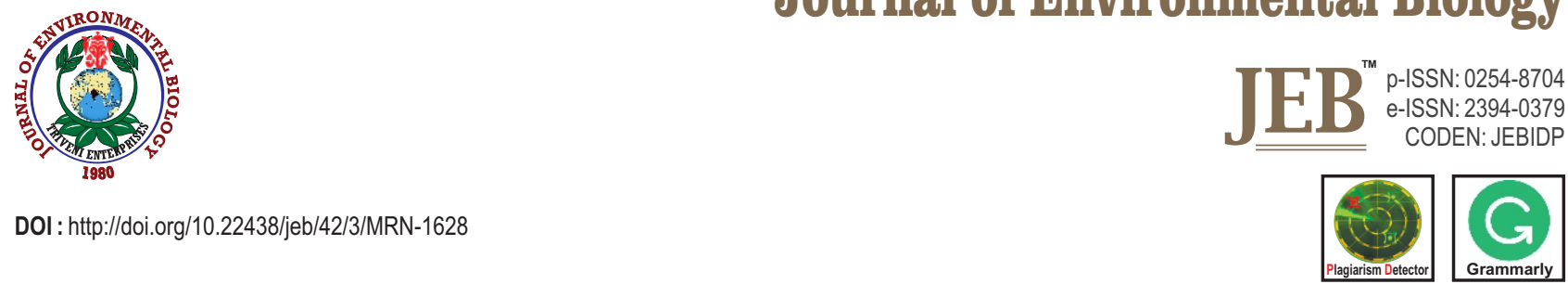

\title{
Invasion of the freshwater snail Physella acuta (Draparnaud, 1805) in selected ponds of North Dinajpur, India
}

\author{
P. Paul and G. Aditya* \\ Department of Zoology, University of Calcutta, Kolkata-700 019, India \\ *Corresponding Author Email : gautamaditya2001@gmail.com
}

\section{Abstract}

Aim: The dispersal and geographical range expansion of globally invasive snail Physella acuta (Draparnaud, 1805) (Gastropoda: Physidae) were little being monitored following the first report from Kolkata, India. An account of the encounter of $P$. acuta in two ponds of North Dinajpur district of West Bengal, India is recorded here.

Methodology: Multiple samples of freshwater snails were collected using aquatic nets from the invaded and non-invaded ponds for assessment and comparison. The shell lengths of the collected $P$. acuta were measured using a vernier calliper to represent size class variations of the population in the ponds.

Results: Varying numbers of $P$. acuta were present in the shoreline and the hydrophytes of littoral zone of invaded ponds. The size class distribution of $P$. acuta indicated the establishment of a stable population in the invaded ponds where a significant difference $(P<0.05)$ was observed in the abundance of a native snail Racesina luteola (Lamarck, 1822) when compared with the abundance in the non-invaded ponds.

Interpretation: Invasion of $P$. acuta in the ponds reflected its ability to overcome the predator-borne barriers and to coexist with the native snails. The geographic range of $P$. acuta seems to have extended, even though slower with reference to the first record in India.

Key words: Aquatic invasion, Freshwater habitat, Invasive species, Native snail, Physella acuta

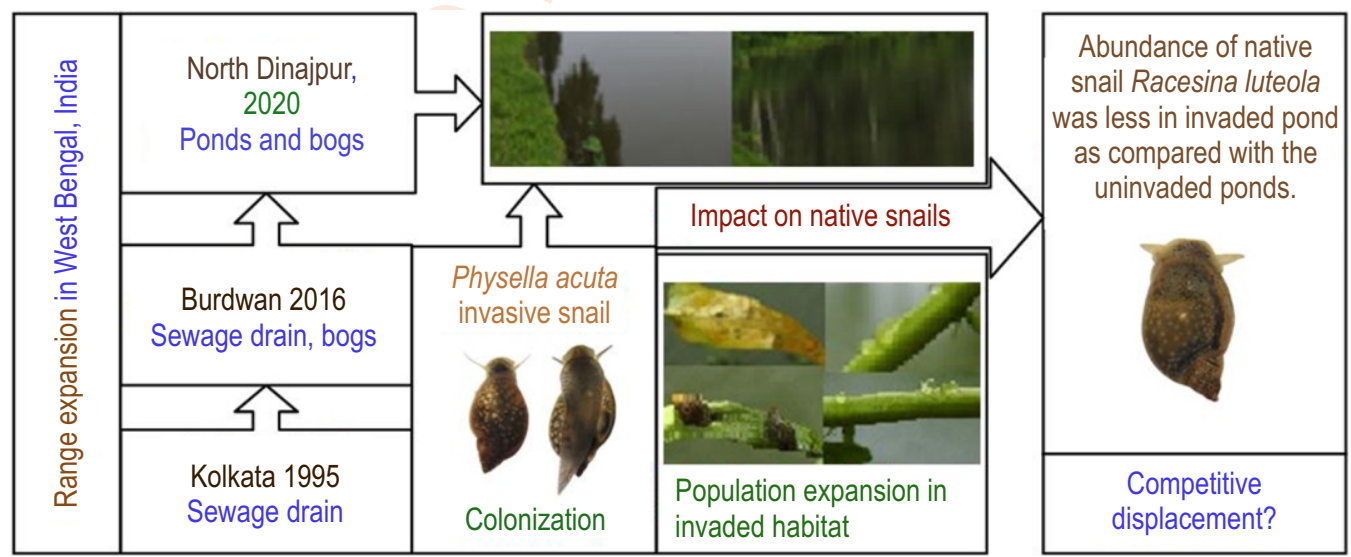

How to cite : Paul, P. and G. Aditya: Invasion of the freshwater snail Physella acuta (Draparnaud, 1805) in selected ponds of North Dinajpur, India. J. Environ. Biol., 42, 577-581 (2021). 


\section{Introduction}

The invasion by the freshwater molluscs in varied water bodies bears immense impacts on the local biodiversity (Karatayev et al., 2009). The acute bladder snail Physella acuta (Draparnaud, 1805) (Gastropoda: Physidae) is a North American pulmonate snail that has invaded all continents, except Antarctica (Zukowski and Walker, 2009; Vinarski, 2017; Cieplok and Spyra, 2020). In India, the presence of live $P$. acuta was observed in Kolkata for the first time (Raut et al., 1995), followed by discrete information from Guwahati, Assam (Devi et al., 2008), Himayatsagar and Osman Sagar in Andhra Pradesh (Karuthapandi et al., 2013), Burdwan, West Bengal (Saha et al., 2016 a, b) and in Budhabalanga river, Odisha (Tripathy and Sajan, 2018). The globally invasive $P$. acuta is found and capable to thrive in a wide range of habitats including highly polluted freshwater bodies, sewage drains and puddles (Saha et al., 2016 a, b; Cieplok and Spyra, 2020). For this reason, P. acuta often exploits newly disturbed habitats better than the native snails (Brackenbury and Appleton, 1993). The post-invasion impacts by $P$. acuta include competition with native snails and their displacement (Zukowski and Walker, 2009), damage of plants having economic importance and capability of transmitting vector-borne diseases (Barragán-Sáenz et al., 2009; Kraus et al., 2014).

Since the first report of $P$. acuta from sewage drains in Kolkata, India, the range expansion was little traced until recently, where the snails were observed from Burdwan, India (Saha et al., $2016 \mathrm{a}, \mathrm{b})$. While the information on the predatory potential of water bugs and leeches (Aditya and Raut, 2002 a, b, c) on P. acuta was documented from Kolkata populations, little effort was made to highlight the population growth and the range expansion of the snail in other regions of India. The estimates of relative abundance of the snail in the sewage drains and puddles in suburbs of Burdwan indicated the dispersal, colonization and establishment beyond the urban boundaries of Kolkata, India. The geographical range expansion can be considered as an indicator of the invasive nature of a species like $P$. acuta (Vianrski, 2017) that tends to show continued colonization and establishment in the newer habitats (Cieplok and Spyra, 2020). Thus, the chance observation of $P$. acuta in the rural ponds of North Dinajpur, West Bengal, India, provided an opportunity to explore the population pattern and the effect on the community, if any. The present narrative is an attempt to provide an overview of $P$. acuta recorded from the ponds in North Dinajpur as evidence of range expansion and suspected impact on the native snail community. The results will be useful in understanding the colonization pattern in the rural areas and enable framing strategies for the management of snails beyond the region of the first record in West Bengal, India.

\section{Materials and Methods}

In the course of a survey of the freshwater snails from different regions of West Bengal, India, random sampling of the ponds and bogs of North Dinajpur was carried out in June 2020. In two of the ponds $\left(25^{\circ} 34^{\prime} 15.8^{\prime \prime} \mathrm{N}, 88^{\circ} 18^{\prime} 27.6^{\prime \prime} \mathrm{E}\right.$ and $25^{\circ} 35^{\prime} 42.1^{\prime \prime} \mathrm{N}$, $\left.88^{\circ} 18^{\prime} 36.1^{\prime \prime E}\right)$, the population of invasive snail $P$. acuta was observed along with other snails. The snails were collected using a sampling net of $200 \mu \mathrm{m}$ mesh size fitted with a long handle. The identification and species-specific confirmation of $P$. acuta were done by observing the morphological features according to Taylor (2003). The snails collected from each pond were sampled in 15 different positions and each sampling comprised of 3 surfing of sampling net in different depths ranging from surface to sediments. Following the same procedure, snails were sampled from adjacent ponds $(n=2)$ having no record of $P$. acuta

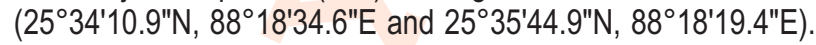
For each sample from the ponds, the collected snails were segregated following identification and recorded for the relative abundance of the representative species. The shell lengths $(\mathrm{mm})$ of $P$. acuta were measured with a vernier caliper (Insize, Brazil) to estimate the size group distribution patterns (population structure) in the invaded ponds. One-way ANOVA was applied to find out if any significant difference was present between the abundance of native snails in the invaded and non-invaded ponds.

\section{Results and Discussion}

The invasive snail $P$. acuta was observed in the littoral zone of the ponds, crawling near the shoreline or on the hydrophytes. The egg capsules were noted on the wet soil near shoreline, stems and leaves of Ipomoea aquatica and the movement of the snails was also observed in the stems and leaves of Alternanthera philoxeroides growing at the edge of the ponds. In 30 discrete samples from both ponds, 143 individuals ( $n=70$ and $n=73$ from two separate ponds) of $P$. acuta were collected through sampling and the size group distribution pattern indicated the presence of stable populations (Fig.1). In the surveyed ponds, snails such as Racesina luteola (Lamarck, 1822) (Heterobranchia: Lymnaeidae), Indoplanorbis exustus (Deshayes, 1834) (Heterobranchia: Planorbidae), Gyraulus convexiusculus (Hutton, 1849) (Heterobranchia: Planorbidae), Bellamya bengalensis (Lamarck, 1822) (Caenogastropoda: Viviparidae), Pila globosa (Swainson, 1822) (Caenogastropoda: Ampullariidae) and Gabbia orcula (Frauenfeld, 1862) (Caenogastropoda: Bithyniidae) were observed in addition to being present with $P$. acuta. Variations in the relative abundance of these snails were observed in both the invaded $(n=30$ discrete samples) and non-invaded ponds ( $n=30$ discrete samples) (Fig. 2 ), but the differences in the abundance pattern were not significant, except for $R$. luteola.

The result of ANOVA indicated that there was a significant difference $\left(F_{1,58}=9.516, p<0.001\right)$ in the abundance of $R$. luteola but not in case of other snails in the presence and absence of the invasive snail $P$. acuta (Fig. 2). Such variations in the relative abundance of $R$. luteola in the presence and absence of $P$. acuta is indicative of possible competition mediated population decline of a native snail as a result of species invasion (Cieplok and Spyra, 2020). In Argentina, P. acuta has successfully established in the freshwater habitats which were previously dominated by 

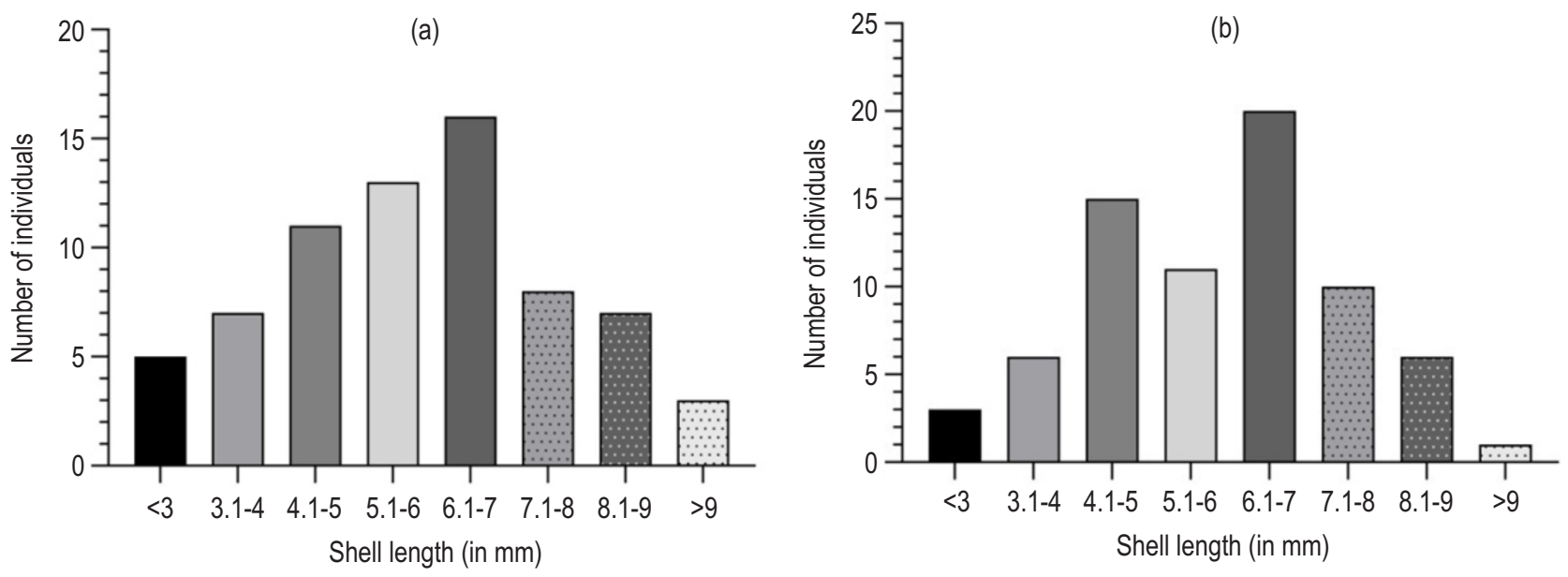

Fig. 1: The number of $P$. acuta belong to different size classes indicates stable established population in two separate ponds, (a) and (b), in North Dinajpur, West Bengal, India. The last three columns belong to the reproductive size classes.
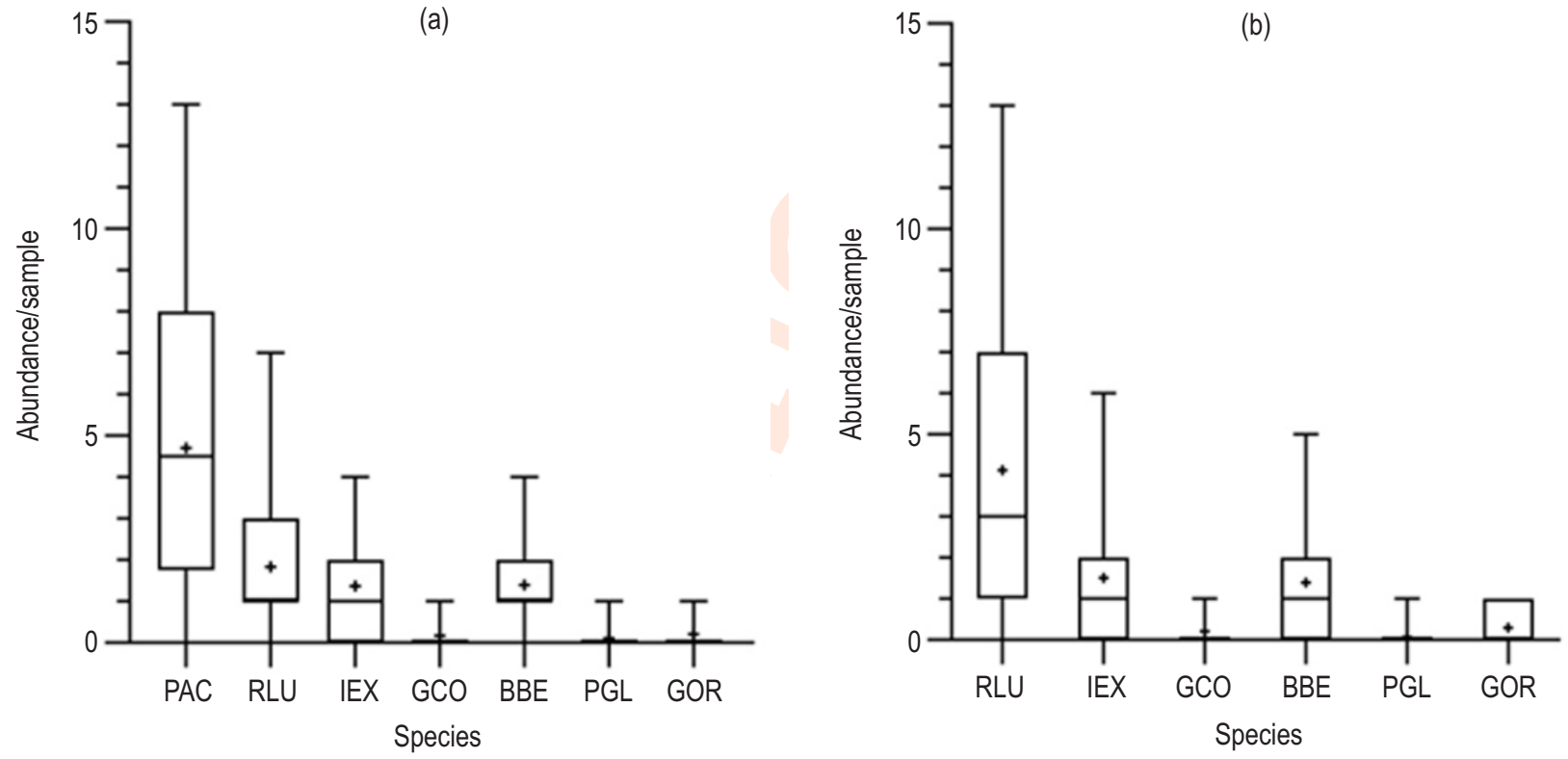

Fig. 2: Comparison between the abundance / sample ( $n=30$ for each type of pond) of different snails found in the ponds (a) with the presence of $P$. acuta and (b) without the presence of $P$. acuta. The abundance/ sample of $R$. luteola was significantly lower in the presence of invasive snail $P$. acuta compared to the ponds where $P$. acuta was absent $\left(\mathrm{F}_{1.58}=9.516, p<0.003\right.$ ). (Acronyms: PAC- $P$. acuta, RLU- R. luteola, IEX- I. exustus, GCO- G. convexiusculus, BBE- B. bengalensis, PGL-P. globosa and GOR- G. orcula).

native snail Stenophysa marmorata (Núñez, 2011). In a similar way, P. acuta declined the population of the morphologically and ecologically similar native snail Glyptophysa gibbosa in the River Murray, South Australia (Zukowski and Walker, 2009). The observations in the present instance are indicative of the possible displacement of native snail $R$. luteola by the invasive $P$. acuta as both the snail species were observed in the shallow littoral zone with vegetations and share similar feeding habits. Therefore, invasion of $P$. acuta in the pond and diverse freshwater wetlands in West Bengal and similar regions of India poses serious risk and concern for the competitive displacement of the native snails like $R$. luteola. In addition, higher tolerance of $P$. acuta to the 
anthropogenic disturbances and adverse ecological conditions (Brackenbury and Appleton, 1993; Cieplok and Spyra, 2020) may provide more advantages over $R$. luteola as many ponds are often subjected to vigorous netting and pesticide exposure (fish ponds) along with fertilizer and pesticide contamination due to agricultural runoff in the rural areas. Such features are highlighted as factors facilitating the colonization and establishment of $P$. acuta (Cieplok and Spyra, 2020). The introduction of $P$. acuta in non-native regions is facilitated by aquarium trade (Vinarski, 2017; $\mathrm{Ng}$ et al., 2016). Once introduced, the ability to adapt in a wide range of habitat conditions and plasticity of life-history traits as higher fecundity and shorter hatching time of eggs than many of the native snails enable $P$. acuta to establish as a superior and successful competitor (Zukowski and Walker, 2009; Núñez, 2011; Dillon and Jacquemin, 2015). This proposition is substantiated through the established colonies of $P$. acuta is sewage drains and the associated puddle of Burdwan (Saha et al., 2016 a, b). Unlike other instances in India, $P$. acuta was observed in the ponds which raise a serious concern about the ill effects on the native snails (Cieplok and Spyra, 2020) as P. acuta appears to extend its range considerably in West Bengal, India in latitudinal scale. However, the malacophagous predators like leeches, insects, crustaceans and fishes may pose a barrier to the establishment of $P$. acuta in the ponds (Ben-Ami and Heller, 2001; Aditya and Raut, 2002 a, b, c; Yamanishi and Yoshida, 2012). It is worth mentioning that the predatory efficacy of leech Glossiphonia weberi and water bug Diplonychus (=Sphaerodema) rusticus seems quite satisfactory against $P$. acuta (Aditya and Raut, 2002 a, b, c). Nonetheless, with the present report, it seems evident that the invasion of $P$. acuta in the ponds reflects that the snails were able to overcome the predator borne barriers for their colonization and establishment in the newer habitats.

Empirical evidence suggests that the foraging pattern and spatial orientation of $P$. acuta vary with the presence of predators like water bugs (Wojdak, 2009). The varied ability of refuge use pattern (surface swimming) by $P$. acuta can be considered as a behavioural manifestation developed to evade predators (Wojdak, 2009) and therefore successfully colonize and establish in newer habitats. Such behavioural pattern and plasticity in the life history traits of $P$. acuta may facilitate in alteration of the native snail population, other macroinvertebrate species and macrophytes composition of the invaded ponds. Thus, a slow yet effective extension of invasion of $P$. acuta has occurred in West Bengal, since the first report from Kolkata, India. Continued surveillance of the freshwater habitats is therefore required to monitor and predict the range expansion of $P$. acuta as well as for framing effective management strategies.

\section{Acknowledgments}

We are grateful to the Head, Department of Zoology, University of Calcutta, Kolkata, West Bengal, India for the facilities provided. PP acknowledges the financial support of CSIR-HRDG, India [09/028(1115)/2019-EMR-1, dated 06/08/2019].

\section{Add-on Information}

Authors' contribution: P. Paul: Field observation, data collection and compilation; G. Aditya: Concept, data analysis and compilation.

Research content: The research content of manuscript is original and has not been published elsewhere.

\section{Ethical approval: Not applicable}

Conflict of interest: The authors declare that there is no conflict of interest.

\section{Data from other sources: Not applicable}

Consent to publish: All authors agree to publish the paper in Journal of Environmental Biology.

\section{References}

Aditya, G. and S.K. Raut: Potential of the leech Glossiphonia weberi (Blanchard) in controlling the sewage snail Physa acuta Draparnaud. Curr. Sci., 83, 1317-1319 (2002c).

Aditya, G. and S.K. Raut: Predation of water bug Sphaerodema rusticum on the freshwater snails Lymnaea (Radix) Iuteola and Physa acuta. Veliger, 45, 267-269 (2002b).

Aditya, G. and S.K. Raut: Predation potential of the water bugs Sphaerodema rusticum on the sewage snails Physa acuta. Mem. I. Oswaldo. Cruz., 97, 531-534 (2002a).

Barragán-Sáenz, F.A., P. Sánchez-Nava, O. Hernandez-Gallegos and G. Salgado-Maldonado: Larval stages of trematodes in gastropods from Lake Chicnahuapan, State of Mexico, Mexico. Parasitol. Res., 105, 1163-1167 (2009).

Ben-Ami, F. and J. Heller: Biological control of aquatic pest snails by the Black Carp Mylopharyngodon piceus. Biol. Contr., 22, 131-138 (2001).

Brackenbury, T.D. and C. Appleton: Recolonization of the Umsindusi River, Natal, South Africa, by the invasive gastropod, Physa acuta (Basommatophora, Physidae). J. Med. Appl. Malacol., 5, 39-44 (1993).

Cieplok, A. and A. Spyra: The roles of spatial and environmental variables in the appearance of a globally invasive Physa acuta in water bodies created due to human activity. Sci. Total Environ., 744, 140928 (2020).

Devi, P., S. Islam and M. Das: Ecology and biology of aquatic snails and their control: I. Comparative biology and development of five freshwater snails from Assam. J. Vet. Parasitol., 22, 9-12 (2008).

Dillon, R.T. Jr. and S.J. Jacquemin: The heritability of shell morphometrics in the freshwater pulmonate gastropod Physa. PLOS ONE, 10, e0121962. doi:10.1371/journal.pone.0121962 (2015).

Karatayev, A.Y., L.E. Burlakova and V.A. Karatayev: Introduction, distribution, spread, and impacts of exotic freshwater gastropods in Texas. Hydrobiologia, 619, 181-194 (2009).

Karuthapandi, M., D.V. Rao and B.X. Innocent: Freshwater mollusc Physella acuta (Gastropoda: Pulmonata) new distributional record from Andhra Pradesh, India. Int. J. Life. Sci. Educ. Res., 1, 54-56 (2013).

Kraus, T., S. Brant and C. Adema: Characterization of trematode 
cercariae from Physa acuta in the Middle Rio Grande. Comp. Parasitol., 81, 105-109 (2014).

Ng, T.H., S.K. Tan, W.H. Wong, R. Meier, S-Y. Chan and H.H. Tan: Molluscs for sale: Assessment of freshwater gastropods and bivalves in the ornamental pet trade. PLOS ONE, 11, e0161130 (2016).

Núñez, V.: Fecundity and survival advantages of an exotic gastropod compared to a native species. Am. Malacol. Bull., 29, 95-103 (2011).

Raut, S.K., S. Bhaumik and S. Das: Occurrence of the snail Physa acuta Draparnaud in Calcutta, India. J. Bombay Nat. Hist. Soc., 92, 434 (1995).

Saha, C., J. Chakraborty, S. Pramanik, S. Parveen and G. Aditya: Observations on the abundance and fecundity of the invasive snail Physa acuta in West Bengal, India: Implications for management. Ecol. Environ. Conserv., 23 (Supple Sept.), S333-S338 (2016b).

Saha, C., S. Pramanik, J. Chakraborty, S. Parveen and G. Aditya: Abundance and body size of the invasive snail Physa acuta occurring in Burdwan, West Bengal, India. J. Entomol. Zool. Stud., 4, 490-497 (2016a).
Taylor, D.W.: Introduction to Physidae (Gastropoda: Hygrophila); biogeography, classification, morphology. Rev. Biol. Trop., 51, 1-263 (2003).

Tripathy, B. and S. Sajan: Moving at a snail pace: Sighting of globally invasive Physella acuta (Draparnaud, 1805) in Budhabalanga River, India (Gastropoda, Physidae). Ellipsaria, 20, 48-49 (2018).

Vinarski, M.V.: The history of an invasion: phases of the explosive spread of the physid snail Physella acuta through Europe, Transcaucasia and Central Asia. Biol. Invasions, 19, 1299-1314 (2017).

Wojdak, J.M.: Foraging and refuge use by a pond snail: Effects of physiological state, predators, and resources. Act. Oecol., 35, 746-751 (2009).

Yamanishi, Y., K. Yoshida and N. Fujimori: Predator-driven biotic resistance and propagule pressure regulate the invasive apple snail Pomacea canaliculata in Japan. Biol. Invasions, 14, 1343-1352 (2012).

Zukowski, S. and K.F. Walker: Freshwater snails in competition: alien Physella acuta (Physidae) and native Glyptophysella gibbosa (Planorbidae) in the River Murray, South Australia. Mar. FreshwaterRes., 60, 999-1005 (2009). 